\title{
Irrigation management in Mediterranean salt affected agriculture: how leaching operates
}

\author{
Angela Libutti, Massimo Monteleone \\ Dipartimento di Scienze Agro-ambientali, Chimica e Difesa Vegetale, Università di Foggia, Italy
}

\begin{abstract}
In the frame of a crop rotation currently applied in a farm of the Apulian Tavoliere (Southern Italy), this paper reports the effect of brackish water irrigation on soil, outlines the corresponding salinity balance, formulates quantitative relations to model salt outflow below the soil root-layer and defines operational criteria to optimize irrigation management at farm level in order to control soil salinity through leaching. The general aim is to contribute to a sustainable use of the available water resources and a proper soil fertility conservation. A three-year trial (2007-2010) was carried out on a farm located close to the coast of the Manfredonia gulf (Mediterranean - Adriatic sea), where irrigation with brackish water is frequently practiced due to seawater intrusion into the groundwater. An especially designed experimental field-unit was set-up: the bottom of three hydraulically insulated plots was covered with a plastic sheet to intercept the percolating water and collect it into tanks by means of drain tubes. Each year a double crop cycle was applied to the soil; a spring-summer crop (tomato, zucchini and pepper, respectively) was followed by a fall-winter crop (spinach, broccoli and wheat). Short fallow periods (completely bare soil) were inserted between two crop cycles. Irrigation or rain completely restored crop water consumptions (with the exception of wheat, considered a rainfed crop) and leaching was performed both unintentionally (by rainfalls) or intentionally (supplying higher irrigation volumes
\end{abstract}

Correspondence: Dr. Massimo Monteleone, Dipartimento di Scienze Agroambientali, Chimica e Difesa Vegetale, Università di Foggia via Napoli 25, 71122 Foggia, Italy. Tel. +39.0881.589223. E-mail: m.monteleone@unifg.it

Key words: brackish water, drainage water, hydro-salinity balance, irrigation management, leaching model, salts leaching, soil salinity.

Acknowledgements: this research was funded by CLIMESCO Evolution of cropping systems as affected by climate change project, contract n. 285, 20/02/2006 (Ministry for Education, University and Research).

Received for publication: 6 April 2011.

Accepted for publication: 11 January 2012.

CC Copyright A. Libutti and M. Monteleone, 2012

Licensee PAGEPress srl, Italy

Italian Journal of Agronomy 2012; 7:e5

doi:10.4081/ija.2012.e5

This article is distributed under the terms of the Creative Commons Attribution Noncommercial License (by-nc 3.0) which permits any noncommercial use, distribution, and reproduction in any medium, provided the original author(s) and source are credited. whenever the soil electrical conductivity exceeded a fixed threshold). The soil electrical conductivity was periodically measured together with volume and electrical conductivity of irrigation and drainage water. All these measures allowed to draw-up the salt-balance of the soil, respectively at the beginning and the end of each crop cycle. Absolute and relative variations in soil salt content were interpreted with respect to absolute and relative drainage volumes according to a three steps procedure of covariance analysis. A simple, general and comprehensive leaching model is thus presented. Results showed that salt build up into the soil can be very rapid, generally occurring within a single irrigated summer crop cycle. Rainfalls of the autumn-winter period had a crucial role in the removal of salts brought into the soil by summer irrigation. This paper strongly emphasises that additional fresh water supply is of great importance to establish acceptable soil conditions. Two suitable periods for intentional leaching were identified.

\section{Introduction}

Irrigated agricultural areas in arid and semi-arid regions of the world frequently suffer from soil salinization because of poor quality water (Tanij, 1990; Maas and Grattan, 1999; Schoups et al., 2005). In these areas, good quality water resources are becoming increasingly scarce and are primarily allocated to civil uses (Bertlan, 1999). Consequently, non-conventional water resources, such as brackish water, often represent an important contribution to narrow the gap between freshwater availability and crop demand.

The Mediterranean coastal areas are a typical example of regions where water resources for agriculture are rather limited and irrigated agriculture is possible using also brackish water. Indeed, several intensively cropped Italian coastal plains are progressively becoming salt affected. Intensive groundwater exploitation together with low precipitations are causing the progressive lowering of the water table and the consequent gradual intrusion of the marine water cone, bringing about a significant increase in water and soil salinity. This is particularly true along the coastal areas of the Apulian region (South Italy), where brackish irrigation water is ordinarily used, determining the risk of secondary soil salinization (Monteleone et al., 2006). An appropriate irrigation management should preserve the root-zone from salinity; on this respect, on-farm irrigation management requires a certain amount of leaching in order to displace excessive soluble salts from the soil profile and ensure soil sustainability (Barnard et al., 2010; Corwin et al., 2007). The leaching requirement has been defined as the minimum amount of the total water supplied that must pass through the soil root zone to prevent excessive salt accumulation (USSLS, 1954). Leaching must not necessarily remove the total salt amount brought into the root-zone by irrigation water; more realistically, the aim should be to keep root-zone salinity within limits that are consistent with an acceptable crop yield, thus minimizing salts affect- 
ing plant growth. Such limits vary considerably according to cropping systems, soil and climate characteristics as well as crop or variety tolerance traits (Rhoades and Loveday, 1990). The combination of all such issues allows to modulate the leaching water application technique.

Leaching efficiency increases at higher soil salinity content (Barnard et al. 2010; Monteleone et al., 2004b): it is therefore recommended that periodic leaching (i.e. not at every watering) should be applied when soil salinity reaches the threshold level capable of interfere with crop yield (Monteleone et al., 2004b; Monteleone, 2006; Hamdy, 2002). Consequently, it is generally accepted that leaching requirement could be satisfied not necessarily during the irrigated cropping cycle but whenever it is believed useful in the course of the year (Chen et al., 2010). Periodic seasonal leaching applications reduce total water consumption compared to continuous leaching because over-irrigation is applied during periods of the year marked by a lower evaporative demand or only whenever soil salinity reaches a level dangerous for the present or following crop. Furthermore, a reduction in the amount of irrigation water supplied to the soil leads to a decrease in the quantity of salt brought into the soil (salinity load) as well as a reduction in the volume and salinity of the leached water that needs to be disposed (Hillel, 2000).

The same advantage results from exploiting the leaching effect of rainfalls. This is particularly true with reference to the Mediterranean climate, characterized by dry summers and rainy autumn-winters (Monteleone et al., 2004a). Exploiting the effect of autumn-winter rainfalls allows to decrease intentional applications of excess saline water and consequently reduce the overall yearly salt load in the soil. When waters of different salinity levels are available, their conjunctive use can follow two different schemes (Hamdy, 1994; Rhoades et al., 1989): blending or alternate cyclic use. It is almost certain that the latter offers several advantages over the former (Letey, 1993): yields are generally higher or not lower (Minhas and Tyagi, 1998); further studies (Naresh et al., 1992; Minhas et al., 1998) have confirmed the beneficial effects of cyclic use, especially when fresh waters are applied during the initial stages of crop establishment. Water of good quality could be applied in the early, more sensitive stages (such as germination and emergence) as well as to promote salt leaching; conversely brackish water could be used during later stages.

A flexible seasonal leaching and a dynamic leaching strategy, promoting salts removal only when soil salinity reaches a threshold level, was experimentally applied, matching water quality, soil characteristics and crop sensitivity with expected productivity and farm economic return. In the frame of a crop rotation commonly applied in the Apulian Tavoliere (Southern Italy), where irrigating with brackish water is a usual practice, this paper reports the effect of brackish water irrigation on soil, outlines the corresponding salinity balance, formulates quantitative relations to model salt outflow below the soil root-layer and, finally, defines operational criteria to optimize irrigation management at farm level in order to control soil salinity through leaching. The general aim was to contribute to a sustainable use of the available water resources and to soil fertility conservation.

\section{Materials and methods}

\section{Experimental set-up}

The trial was carried out in the north-eastern part of the Apulia region (Southern Italy), a Mediterranean area in the Foggia district, during the period $2007-2010$. The experimental field $\left(41^{\circ} 34^{\prime} \mathrm{N}, 15^{\circ} 43^{\prime}\right.$ E ) is located $15 \mathrm{~km}$ from the coast of Manfredonia gulf (Adriatic sea) within a cereal-vegetables farming system.

The experimental set-up was arranged in autumn 2006; it included (Figure 1) three adjacent and identical plots of $100 \mathrm{~m}^{2}$ (6.4 m wide and
$15.6 \mathrm{~m}$ long). At the center of each plot, an artificial draining basin was arranged; it was obtained by digging the soil out of a trench of $50 \mathrm{~m}^{2}$ ( $3.2 \mathrm{~m}$ wide and $15.6 \mathrm{~m}$ long), at the depth of $0.70 \mathrm{~m}$, covering the bottom of each trench with a plastic sheet in order to prevent water percolation and installing a set of draining pipes (two groups per trench, three drains per group) over the plastic cover, in order to collect the percolating water. Each set of drains was connected to a tank placed at one edge of the plot (two tanks per plot) in order to drain away the percolating water. The trenches were filled with the same soil obtained by the excavating procedure, trying to correctly reproduce the original soil stratification.

As a result of this experimental set-up, the natural soil hydraulic gradient is disrupted and a water-saturated zone must form at the bottom of each basin before water can drain. This condition mimics the presence of a shallow water table $0.7 \mathrm{~m}$ deep. The use of an experimental set-up arranged in this way permits to elaborate a soil hydro-salinity balance, over several cropping seasons, in order to check and fine-tune a correct irrigation management.

The experiment was carried out on a loam soil (sand 45.8\%; silt $34.3 \%$; clay 19.9\%), with an organic matter content equal to $1.6 \%$; a total $\mathrm{N}$ content of $1.08 \% 0$ (Kjeldahl method) and a $\mathrm{P}_{2} \mathrm{O}_{5}$ content of 62.4 ppm (Olsen method). The water content (w/w) at field capacity $(-0.03$ $\mathrm{MPa}$ ) was equal to $29.9 \%$ and at wilting point (-1.5 MPa) to $17.4 \%$. The initial values of soil $\mathrm{pH}$ and $E C_{e}$ (EC of the soil saturation water extract) were, respectively, 7.6 and to $2.5 \mathrm{dS} \mathrm{m}^{-1}$.

\section{Experimental crop rotation}

Each cropping year can be split into two growing periods, a springsummer $(S 1)$ and an autumn-winter (S2) season, respectively. The limits of these periods are defined according to the main characteristics of the Mediterranean climate, particularly to the rainfall distribution over the median year (Figure 2). $S 1$ approximately begins at the spring equinox (the $21^{\text {st }}$ of March, $81 \mathrm{DOY}$ - day of the year), at the time when the median monthly rain becomes lower than the annual mean, as showed in Figure 2; the first annual sowings are generally prepared at that time and completed few weeks later. $S 2$, by contrast, conventionally begins at the autumn equinox (the $21^{\text {th }}$ of September,

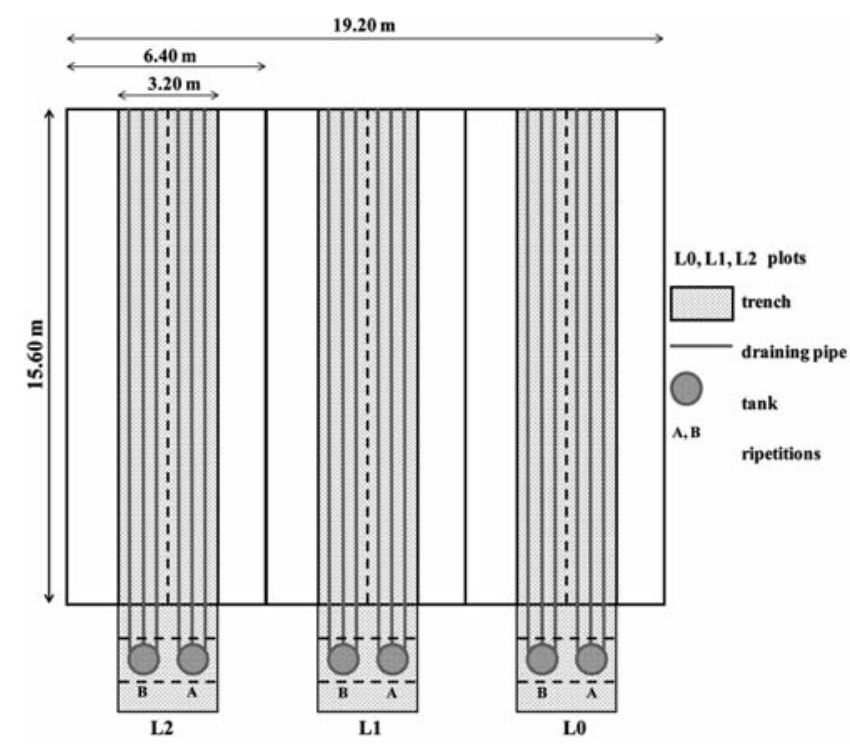

Figure 1. Experimental set-up: three adjacent plots $(L O, L 1$ and L2) having an area of $100 \mathrm{~m}^{2}$ each; a trench of $50 \mathrm{~m}^{2}$ at the centre of each plot; two groups of draining pipes per trench (A and B); three drains per group connected to tanks. 

annual value (Figure 2).

Each seasonal period $S$, in turn, consists of two sub-phases, $C$ and $F$; in the first sub-phase a vegetable crop $(C)$ is grown, while in the second, after crop harvesting, a sort of fallow period $(F)$ occurs, with the soil left completely bare, frequently removing occasional weeds. Figure 3 displays this kind of temporal arrangement. Two cropping cycles are thus identified in the course of a year: $C 1$ and $C 2$; the dry and hot $C 1$ can only be carried out with a regular irrigation supply, while $C 2$ generally involves only supplementary irrigation, when needed. In the third year of trial, being wheat the $C 2$ crop, $F 2$ was completely suppressed (Figure 3). Salinity hazard is strictly related to the summer period (C1 crop), when the use of a large amount of brackish irrigation water leads to salt build-up into the soil; differently, the autumn and winter period could be very useful to promote salt leaching from the soil, thus re-establishing the salt balance.

In the course of the trial, from spring 2007 to spring 2010, the following $C 1$ and $C 2$ crop were respectively cultivated: tomato (Lycopersicon esculentum Mill) and spinach (Spinacia oleracea L.), on 2007-2008, followed by zucchini (Cucurbita pepo L.) and broccoli (Brassica oleracea L. var. italica Plenk), on 2008-2009, and finally pepper (Capsicum annuum L.) and wheat (Triticum durum L.), on 2009-2010, (Figure 3). All the cropping operations were carried out according to the ordinary local farming techniques. Thus, fertilization as well as weed and pest control were accomplished according to currently management practice; crop rotation and the related choice of crop varieties were also determined according to the criteria usually adopted by local farmers.

\section{Experimental treatments}

Three Leaching treatments ( $L O, L 1$ and $L 2)$ were planned according to the following criteria: $L O$ was the control and brackish groundwater was always supplied without any leaching fraction application; in $L 1$ brackish groundwater was always supplied but intentional leaching was applied each time soil conductivity exceeded a fixed threshold; finally, in $L 2$, in addition to brackish groundwater, an amount of freshwater not exceeding $200 \mathrm{~mm}$ per year was eventually available for crop irrigation or intentional leaching.

A critical $E C_{e}$ threshold value $\left(E C_{t}\right)$ was set for each crop; it approximately corresponded to a $20 \%$ reduction in the estimated crop yield, according to the model proposed by Mass and Hoffman (1977). For zucchini the $E C_{t}$ was set at $6.8 \mathrm{dS} \mathrm{m}^{-1}$; for tomato and broccoli it was equal to $5.0 \mathrm{dS} \mathrm{m}^{-1}$; for spinach it was fixed at $4.6 \mathrm{dS} \mathrm{m}^{-1}$; pepper is more sensitive to soil salinity and the threshold was set at $3.0 \mathrm{dS} \mathrm{m}$; finally, referring to wheat, a more resistant crop to salinity, a threshold value equal to $11.0 \mathrm{dS} \mathrm{m}^{-1}$ was assumed.

Irrigation scheduling (times and volumes of water supplied to the crops) was performed according to the soil water balance approach. Therefore, the gravimetric soil moisture was periodically measured; the reference evapotranspiration $E T_{0}(\mathrm{~mm})$ was daily calculated according to the FAO version of the Penman-Monteith equation (Allen et al., 1998); the maximum crop evapotranspiration $E T_{c}(\mathrm{~mm})$ was daily estimated according to the classical two-step procedure, multiplying the reference crop evapotranspiration by the crop coefficient $K_{c}$. The applied crop coefficients were those proposed by the FAO Irrigation and Drainage Paper N. 56 (Allen et al., 1998). The amount of applied irrigation water and the volumes of collected drainage water were regularly recorded. Full $E T_{c}$ restorations were performed each time the soil water depletion reached a threshold value equal to $50 \%$ of the crop available water; the amount of water supplied with irrigation re-established the soil water content to field capacity. Wheat was the only crop totally rainfed.

Whenever soil salinity $E C_{e}$ exceeded the crop threshold value $E C_{t}$, leaching was performed and an extra amount of water (as compared to the estimated $E T_{c}$ ) was applied. Therefore, the irrigation volume was
Jan Feb Mar Apr May Jun Jul Aug Sep Oct Nov Dec

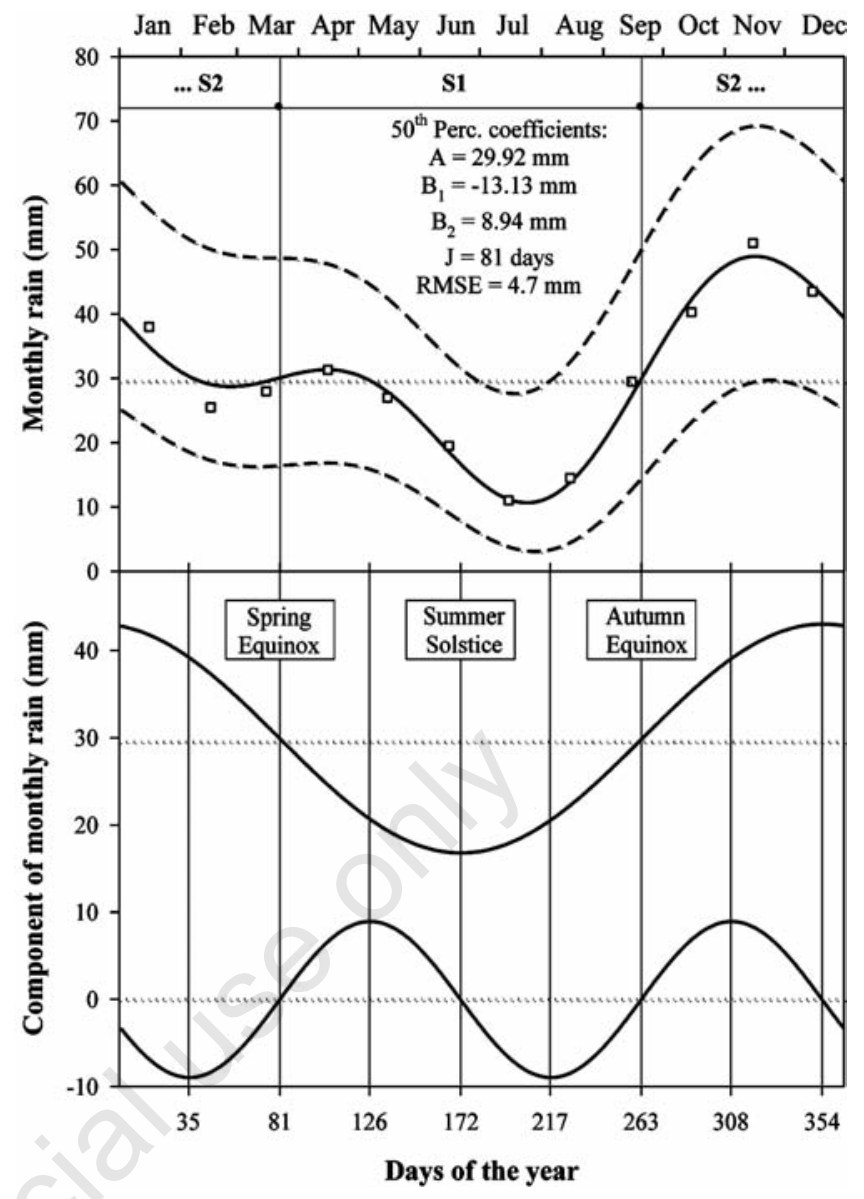

Figure 2. Time-course of rainfalls expressed as monthly precipitations $(\mathrm{mm})$ related to the long-term period 1921-2003. Open symbols are monthly median values $\left(50^{\text {th }}\right.$ percentile) fitted by the solid curve; the two dashed lines indicate the $25^{\text {th }}$ (lower) and 75 th (upper) percentile, respectively. The horizontal dotted line shows the monthly average value (A coeff.). $S 1$ and $S 2$ correspond to the spring-summer and fall-winter period, respectively. The graph below shows the two additive periodic curves that account for the time course of rainfalls; they were obtained through Fourier decomposition analysis whose coefficients are also reported.

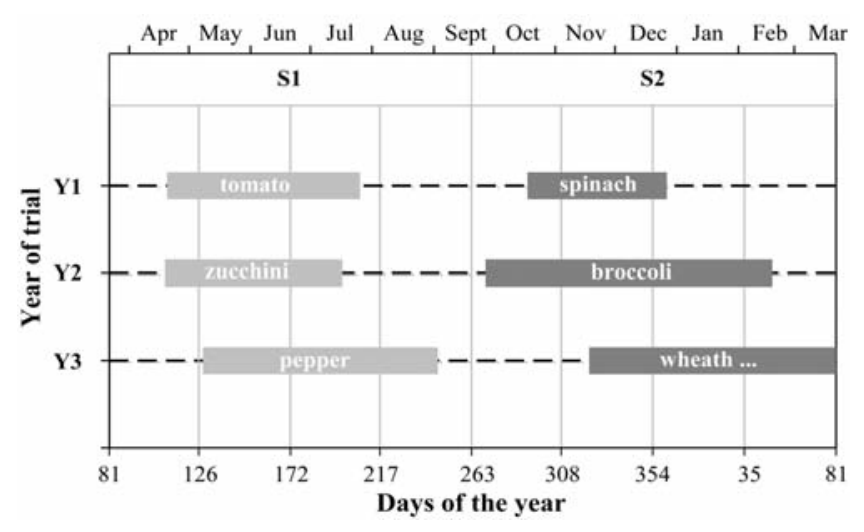

Figure 3. Time arrangement and length of each cropping cycle with respect to the two growing season $(S)$ and the three years of trial $(Y)$. N.B. the wheat cropping cycle goes beyond $Y 3$ also involving $Y 4$. 
increased by a leaching fraction $(L F)$ calculated considering the electrical conductivity of the irrigation water $\left(E C_{i w}\right)$, according to the following equation (van Hoorn and van Alphen, 1994; Monteleone, 2006):

$$
L F(\%)=100 * E C_{i w} /\left(2 * E C_{t}\right)
$$

Groundwater used for irrigation was characterized by an electrical conductivity $E C_{i w}$ that ranged from 4.7 to $5.8 \mathrm{dS} \mathrm{m}^{-1}$; it progressively increased in the course of the summer period. A dripping irrigation system was employed, with twelve dripping lines per plot placed at a distance of $0.5 \mathrm{~m}$; emitters were installed every $0.4 \mathrm{~m}$ along the lines, with a flow rate of $3 \mathrm{l} \mathrm{h}^{-1}$. A water meter was inserted at the head of the irrigation system to record the amount of water supplied.

\section{Soil and water sampling}

During the cropping cycles and the fallow periods a set of determinations were carried out on soil as well as on irrigation and drainage water. Gravimetric moisture (w/w), $\mathrm{pH}$ and $E C_{e}$ were monitored in the soil. As to water (both irrigation and drainage), $\mathrm{pH}$ and electrical conductivity were determined ( $E C_{i w}$ and $E C_{d w}$ respectively). Soil samplings were extracted from each plot, each time in two randomly selected sites and at three different depths $(0.20-0.40-0.60 \mathrm{~m})$; samplings were performed every 10 days along the cropping season $(C)$ and every 20 days during the fallow periods $(F)$. On each soil sample, wet and dry weight was determined, the latter till a constant weight was reached inside an air-forced oven at the temperature of $105^{\circ} \mathrm{C}$. Due to the large number of soil samples to be analysed, soil electrical conductivity was determined on the filtrate of a 1:2 soil-water suspension $\left(E C_{1: 2}\right)$, this procedure being less time-consuming compared to the water extraction procedure of a saturated soil sample. Then, in order to convert $E C_{1: 2}$ in $E C_{e}$, an empirical, multiple linear regression considering the percentage of clay and silt in the soil was used (Monteleone et al., 2003). Soil pH was determined on the filtrate of a 1:2.5 soil-water suspension.

ESP on soil and SAR on irrigation and drainage water were periodically calculated; these data are not presented in this paper; on the base of their values, however, it is possible to assert that the effect of sodium on soil (sodicity) was never significant. Groundwater was sampled in three random repetitions every time it was applied to crops; drainage water was collected in the tanks and sampled in three random repetitions from each tank whenever drainage occurred. Electrical conductivities were measured with an EC-Meter GLP 31+, CRISON; pH was measured with a pH-\& Ion Meter GLP 22+, CRISON.

In order to estimate $E T_{0}$ and to periodically update the water balance, meteorological data were daily recorded by means of a weather station placed close to the experimental field. The recorded variables (maximum and minimum values) were: air temperature $\left({ }^{\circ} \mathrm{C}\right)$, air humidity $(\%)$, wind speed $\left(\mathrm{m} \mathrm{s}^{-1}\right)$, rain $(\mathrm{mm})$; they were acquired every $10 \mathrm{~min}$, averaged and recorded every $30 \mathrm{~min}$ by a data logger.

\section{Data analysis and statistical procedures}

In this paper only a few of the collected data will be presented; according to criteria already presented in Libutti $e t$ al. (2008), different kinds of data sources and variables have been considered here: i) $E C_{e}$ values along the soil profile and during the three-year experimental trial (respectively at the beginning and at the end of each Season $S$ ); ii) water volumes into and out the soil as well as their corresponding $E C_{i w}$ and $E C_{d w}$ values, in order to compute the amount of salts $\left(t h a^{-1}\right)$ respectively added $\left(S_{I N}\right)$ and subtracted $\left(S_{\text {OUT }}\right)$; as a consequence, the temporal variations in soil salt content $\Delta S\left(t h a^{-1}\right)$ were determined. The soil salt load $S_{L O A D}\left(t h a^{-1}\right)$ was computed as the sum of the initial salt content of the soil $S_{0}$ and the salts supplied to the soil by irrigation $S_{I N}$. The soil relative salt variation $\Delta S_{0}$ is equal to the ratio $\Delta S / S_{0}$ while the salinity ratio $S R$ is expressed as the ratio of $S_{\text {OUT }}$ over $S_{L O A D}$; the relative leaching $(R L)$, in conclusion, is defined as the volumetric fraction of drainage water $(D)$ over the total water supply $(W)$, namely the sum of rain $(R)$ and irrigation $(I)$ water. The latter three variables $\left(\Delta S_{0}, S R\right.$ and $R L$ ) can conveniently be expressed as percentages.

Absolute and relative variations in soil salt content were interpreted with respect to absolute and relative drainage volumes according to a three steps procedure of covariance analysis (ANCOVA).

First step: with reference to both growing seasons ( $S 1$ and $S 2$ ), the variations in soil salt content $\Delta S$ were linearly related to the corresponding drainage volumes $D$ collected from the tanks. Considering that an initial amount of drainage water can remove more salts than the following amounts, leaching turns out to be increasingly difficult as more water volumes pass through the soil profile; for this reason, a decimal logarithm transformation of drainage volumes was performed, according to the following formula: $D_{t r}=\log (D+1)$. The addition of the unit value to $D$ is necessary in order to prevent an impossible solution in case of $D=0$ as well as to assign a physical meaning to the intercept value.

Second step: still with reference to both growing seasons, the relative variations in soil salt content $\Delta S_{0}$ were linearly related to the corresponding relative leaching volumes $R L$.

Third step: the same as before, but $\Delta S_{0}$ values were replaced by $S R$ values as a function of the relative leaching volumes $R L$.

A full factorial statistical ANCOVA model was applied, taking into account Year $(Y)$, Season $(S)$ and Leaching treatments $(L)$ as experimental factors. The first model (expressed in absolute terms) is useful to assess the leaching process as actually influenced by the three experimental factors and their combinations. The other two models (expressed in relative terms) are intended to define a generalized, unique and comprehensive leaching pattern not influenced by any variable but $R L$ (taken as statistical regressor).

\section{Results}

\section{Rain, irrigation and drainage}

Considering the great relevance of rainfalls in promoting soil leaching, a climatic analysis was performed in order to represent the precipitation pattern over a long stretch of time (1921-2003). The ordinary time-course of precipitation is reported in Figure 2, expressed in terms of moving average of rainfalls over a time window of 31 days. The Fourier decomposition analysis allowed to interpret the precipitation regime as the superposition of two (and simply two) different periodic curves. The first one, with a semi-amplitude oscillation $\left(B_{1}\right)$ of approximately $13 \mathrm{~mm}$, is perfectly tuned to the alternation of a dry (springsummer) and a wet (autumn-winter) season, according to the phase coefficient $(J)$ equal to $81 \mathrm{DOY}$, corresponding to the spring equinox (the $21^{\text {st }}$ of March); the second curve, with a semi-amplitude oscillation $\left(B_{2}\right)$ of approximately $9 \mathrm{~mm}$, can be considered as an intra-seasonal modulation, allowing a rain increase during spring with respect to summer and during autumn with respect to winter. From Figure 2 is possible to derive that $63 \%$ of the total annual precipitation is usually distributed in $S 2(221 \mathrm{~mm})$ while the remaining $37 \%$ in $S 1(131 \mathrm{~mm})$, with respect to a yearly amount equal to $352 \mathrm{~mm}$.

With regard to the rain amounts occurred during the three-year trial in each seasonal period ( $S 1$ and $S 2$ respectively), significantly higher precipitations as compared with the median long-term amount were detected (Figure 4A), both in $S 1(+26,+126 \mathrm{~mm}$, in $Y 2$ and $Y 3$ respectively) and in $S 2(+52,+228,+113 \mathrm{~mm}$, in the three consecutive years). Due to extraordinary rainy fall-winter periods $(S 2)$, particularly with respect to the second and third year of trial, salt leaching was considerably favoured. This can be considered an exceptional and very unlikely event in the Mediterranean climate. 
Water amounts applied as irrigation and extra-irrigation (i.e. intentional leaching) in the course of the trial are given in Figure 4B. Spring-summer crops were regularly irrigated: tomato, zucchini and pepper profited of a seasonal water supply equal to 544, 356 and 499 $\mathrm{mm}$, respectively. In the course of tomato and zucchini cropping cycles ( $Y 1$ and $Y 2$ respectively), no leaching was applied because the fixed critical $E C_{t}$ value was reached only at the end of cropping season, when the crops were not particularly vulnerable to soil salinity. On the contrary, during the pepper cropping cycle (Y3), the critical $E C_{t}$ was reached 40 days after transplanting and the application of an extra-irrigation volume was therefore needed.

In the first year, autumn rainfalls completely satisfied spinach water requirements and no irrigation was needed along the cropping cycle; the situation was different for broccoli, on the second year of trial: during the first 40 days after transplanting irrigation was supplied to the crop. At the same time, the critical $E C_{t}$ was reached, mostly as a result of the brackish irrigation water applied to the previous crop (C1-zucchini). As a consequence, a leaching application was performed. Wheat (Y3) was considered a rainfed crop. At the end of the first fallow period ( $F 1$, first year of trial: from tomato harvesting to spinach sowing) a presowing watering was applied to the three plots $(L O, L 1$ and $L 2)$. This watering supplied a brackish water amount of $63 \mathrm{~mm}$. The aim of this pre-sowing irrigation was to bring soil moisture to field capacity to facilitate the subsequent leaching due to seasonal rains. Again, in the following experimental year, at the end of the first fallow period ( $F 1$, second year of trial: from zucchini harvesting to broccoli transplanting) an amount of $150 \mathrm{~mm}$ brackish water and $110 \mathrm{~mm}$ fresh water was applied, on $L 1$ and $L 2$ respectively, with the aim of obtaining a preliminary leaching before the incoming autumn rainfalls. Total drainage amounts collected during each $S$ period are reported in Figure 4C. Considering the spring-summer cropping seasons (S1), drainage water amount was much higher during the third year (Y3) than in the first (Y1) and the second (Y2): 165 vs 61 and $45 \mathrm{~mm}$ respectively. As to the $S 1$ period of the third year, the large drainage volumes collected were mostly the result of the leaching application along the pepper cropping cycle.

The fall-winter period (S2) accounted for a very large drainage volume in the second year of trial. In these period, as a consequence of the abundant rainfalls, an impressive quantity of drainage water, amounting to $228 \mathrm{~mm}$, was collected. The same seasonal period accounted for more limited drainage volumes both in the first $(86 \mathrm{~mm})$ and in the third (52 mm) year of trial.

\section{Salinity along the soil profile}

Variations in $E C_{e}$ along the soil profile during the three-year trial are showed in Figure 5. The periodical dynamic of soil salinity is clearly showed; it is the consequence of the balance between water supplies (irrigation and rain) and drainage. Two separate phases can be recognized in the course of each cropping year: a salt accumulation phase (recharge) and a salt removal phase (discharge).

$E C_{e}$ considerably increased along the soil profile at every $S 1$ period (recharge), as a result of the salt load due to irrigation with brackish water. A reverse behaviour was observed in $S 2 ; E C_{e}$ appreciably decreased along the soil profile (discharge) due to autumn and winter rains. Not every year the salts recharged into the soil were counterbalanced by the salts discharged from the soil to reach an equilibrium condition (Figure 5). In the first year of trial (YI), the autumn-winter rains were not sufficient to ensure a complete salt leaching along the soil profile; indeed, a salt displacement from the top to the bottom of the soil was observed. The exceptional amount of precipitation occurred in the second year of trial (Y2) greatly favoured leaching; a consequent and significant reduction in the soil $E C_{e}$ at all depths occurred, thus soil salinity profile levelled off completely. In the third year of trial (Y3), salt discharge due to drainage occurred at all considered depth and a condition of soil salinity equilibrium was attained.

\section{Leaching modelling}

The output of the ANCOVA is made of a set of linear regressions (GLM - general linear model) whose coefficients (intercepts and slopes) are statistically discriminated. Table 1 summarises the statistical results of the three ANCOVA models in terms of $F$-ratio and their corresponding probability, for each experimental treatment (Year, Season, Leaching) and their factorial combinations.

The first applied model ( $\Delta S$ as a function of $D_{t r s f}$ ) resulted highly significant $\left(\mathrm{R}^{2}=0.98 ; \mathrm{P}<0.0001\right)$ and of quite good precision (RMSE $=1.71$ $\left.t h a^{-1} ; \mathrm{CV}=35,4 \%\right)$. A highly significant influence on the model coefficients was displayed by the Season and by the Year, both on the inter-

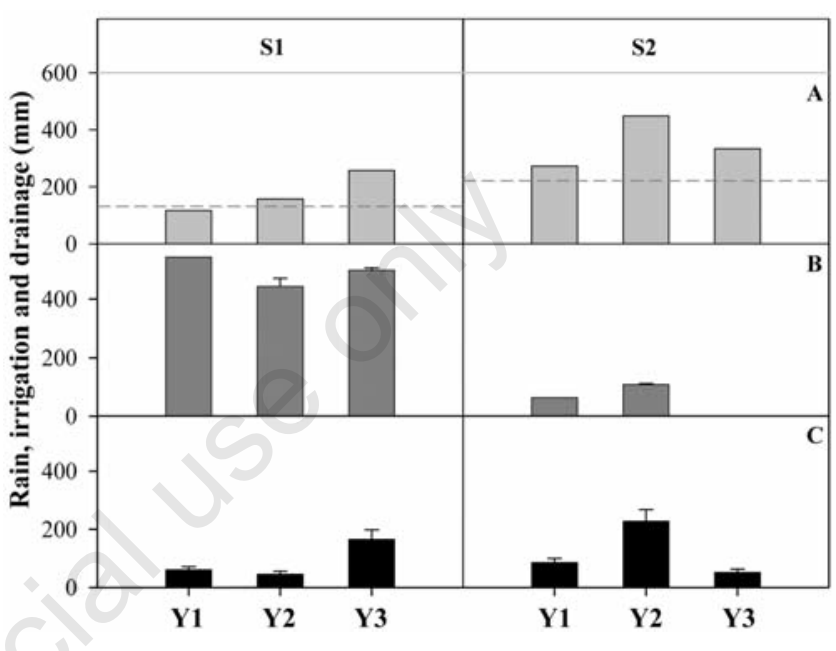

Figure 4. Amount of rain (A), irrigation (B) and drainage (C) with respect to the two growing season $(S)$ and the three years of trial $(Y)$. Horizontal dashed lines (in A) refer to the median long-term seasonal values of precipitations.
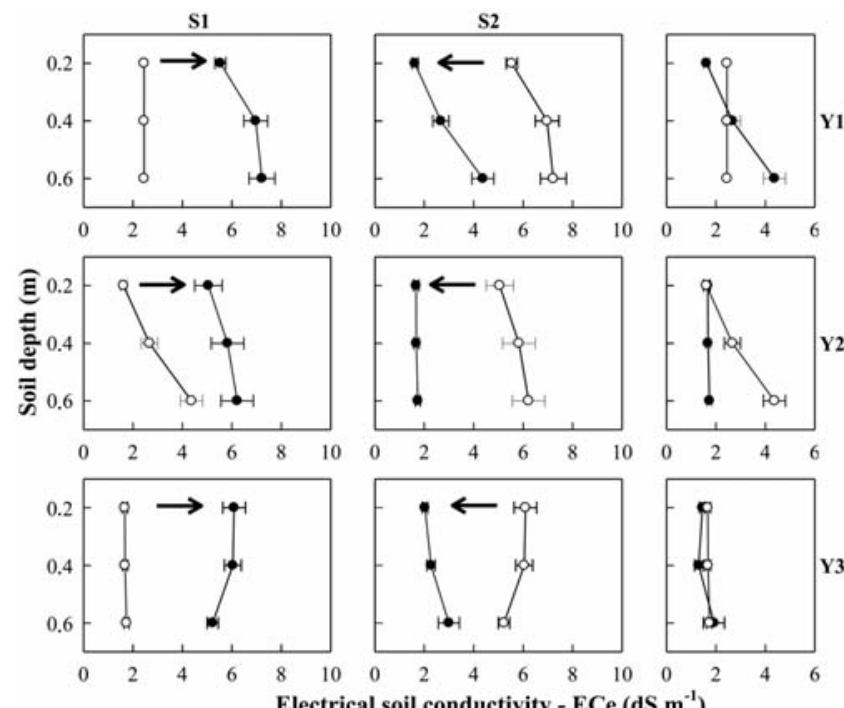

Electrical soil conductivity - ECe $\left(\mathrm{dS} \mathrm{m}^{-1}\right)$

Figure 5. Salinity along the soil profile $(0.20,0.40$ and $0.60 \mathrm{~m}$ of depth) expressed in terms of electrical conductivity of the soil saturated water extract $E C_{e}\left(\mathrm{dS} \mathrm{m}^{-1}\right)$ with respect to spring-summer $(S 1)$ and autumn-winter $(S 2)$ seasons as well as the whole year $(Y)$. Empty and full dots refers to the initial and final conditions of every period, respectively. Horizontal bars indicate the standard error of the mean. 
cept and slope values. Also their interactions showed highly significant values. The intercept value of the model can be interpreted as the total amount of salt built up in the soil as a consequence of brackish irrigation along the season; the slope value, on the other hand, explains the leaching effectiveness, that is the amount of salts that are discharged from the active soil profile by a (log transformed) unit volume of drained water. According to those definitions, $S 1$ greatly increased the average value of the intercept (to $13.28 t h a^{-1}$ on average), while $S 2$ resulted in a much lower value (1.92 $t h a^{-1}$ on average). This kind of results related to the intercept value can be explained considering that, in $S 1$, crop irrigation is absolutely required and systematically performed using brackish water (thus the intercept is always significantly positive, irrespective of the year of trial) while in $S 2$ irrigation has only a supplementary function, so that no or limited amount of salts are added to the soil (thus the intercept is usually zero or slightly positive). Considering the slope coefficient, $S 2$ showed a remarkable lower (more negative) slope compared to $S 1$ ( $-2.60 \mathrm{vs}-1.07$ on average); this result can be interpreted with the fact that leaching in $S 2$ is normally worked out by rain water, while in $S 1$ by the irrigation brackish water. As a consequence, autumn and winter leaching are more effective than leaching performed in the spring-summer period. The effect of Leaching is significant on the intercept values but not significant on the slope coefficient; the $L 1$ intercept is always significantly higher than in $L O$ and $L 2$, because in $L 1$ leaching is performed adding extra-volumes of brackish water. Although statistically not significant, a general trend in promoting salt removal in $L 1$ and $L 2$ is observed by their slope values, lower (more negative) than the corresponding $L O$ value. The model (with respect to the Season effect only) is showed in Figure 6A.

The second model ( $\Delta S_{0}$ as a function of $R L$ ) also resulted highly significant $\left(\mathrm{R}^{2}=0.88 ; \mathrm{P}<0.0001\right)$ but quite rough in precision ( $\mathrm{RMSE}=34.64 ; \mathrm{CV}=68.2 \%) . \Delta S_{0}$ is the ratio of the variation of soil salt content $(\Delta S)$ and the initial soil salt content $\left(S_{0}\right)$. Season is the only factor that greatly influenced the intercept value, almost doubled in $S I$ (122.9\%) compared to the average value while in $S 2$ it was not significantly different from zero $(9.6 \%$, Prob. $=0.22)$. The model (with respect to the Season effect only) is showed in Figure 6B. Differently from the first model, the slope was not considerably influenced either by Season,
Year, or Leaching; the two lines being statistically parallel one to the others. This is directly the consequence of the standardization of $\Delta S$ into $\Delta S_{0}$, and can be considered as a step forward on the way to a unifying leaching model. Leaching, therefore, is greatly influenced by the initial amount of salt in the soil $\left(S_{0}\right)$, but it also could be greatly affected by the quantity of salts actually supplied to the soil during the cropping cycle, when irrigation with brackish water is performed; this means that the salinity ratio $(S R)$ could be the unifying variable we are looking for; the $S R$ values, indeed, depend on the salinity load $\left(S_{L O A D}\right)$ that, as we already know, is the sum of $S_{0}$ and $S_{I N}$.

The third model ( $S R$ as a function of $R L$ ), explained a significant fraction of the total deviance $\left(\mathrm{R}^{2}=0.99 ; \mathrm{P}<0.0001\right)$ and showed a very good degree of precision (RMSE=3.00; $\mathrm{CV}=24.8 \%$ ). This time, as was expected, no significant influence was displayed by Season, Year and Leaching, both on the intercept and slope coefficients; as a consequence, $S_{0}$ and $S_{I N}$ greatly affected leaching and a unique and comprehensive regression line (passing through the origin) can be set to quantitatively describe salt accumulation into and removal from the soil. The slope value is 1.28 (no unit) as reported in Figure 6C.

Considering our experimental conditions, an average annual salinity value $\left(S_{0}\right)$ of approximately $18 t h a^{-1}$ can be assumed (corresponding to an $E C_{e}$ value of $\left.5.0 \mathrm{dS} \mathrm{m}^{-1}\right)$. A seasonal irrigation of approximately $500 \mathrm{~mm}$ of brackish water $\left(E C_{i w}=5.0 \mathrm{dS} \mathrm{m}^{-1}\right)$ brings about an annual salt addition $\left(S_{I N}\right)$ equal to $16 t h a^{-1}$; it means that the same amount of salt should be removed by leaching in the course of the year $\left(S_{\text {OUT }}\right)$. The proper balance salinity ratio $\left(S R^{*}=100 \times S_{\text {out }} /\left(S_{0}+S_{I N}\right)\right.$ thus corresponds to $47 \%$. Applying our general leaching model $(S R=1.28 * R L)$, the annual leaching requirement to be targeted $\left(R L^{*}\right)$ is equal to $37 \%$. According to this conditions, an annual steady-state soil salinity needs that D, the amount of drainage water, should be the $37 \%$ of W, the total water supplied, sum of irrigation $(500 \mathrm{~mm}$ ) and rain (average value equal to $352 \mathrm{~mm}$ per year). An effective leaching supply of, at least, 310 $\mathrm{mm}$ of fresh water are therefore needed in order to assure salt balance. If $200 \mathrm{~mm}$ of brackish water are also available as extra-irrigation supply $\left(S_{I N}=22.4 t h a^{-1}, S R^{*}=55 \%\right.$ and $\left.R L^{*}=43 \%\right)$, the net effective fresh water needed in order to accomplish salt balance is reduced to approximately $170 \mathrm{~mm}$.

Table 1. Statistical results of the three full factorial ANCOVA models ( $\Delta S$ vs $\left.D, \Delta S_{0} v s R L, S R v s R L\right)$. For each factor (Year, Season and Leaching) and factors interaction, F-Ratio and the corresponding Probability are reported. Summary of fit is showed in the lower part of the table.

\begin{tabular}{|c|c|c|c|c|c|c|c|}
\hline \multirow[b]{2}{*}{ Source } & \multirow[b]{2}{*}{ DF } & \multicolumn{2}{|c|}{$\triangle S$ vs $D$} & \multicolumn{2}{|c|}{$\Delta S_{0}$ vs $R L$} & \multicolumn{2}{|c|}{$S R$ vS RL } \\
\hline & & F Ratio & Prob $>F$ & F Ratio & Prob $>F$ & F Ratio & Prob $>F$ \\
\hline \multicolumn{8}{|l|}{ Intercept } \\
\hline Year & 2 & 5.02 & 0.01 & 0.18 & 0.84 & 0.33 & 0.72 \\
\hline Season & 1 & 398.11 & $<0.001$ & 106.54 & $<0.001$ & 0.54 & 0.47 \\
\hline Year; season & 2 & 9.84 & 0.00 & 0.47 & 0.63 & 0.08 & 0.92 \\
\hline Leaching & 2 & 3.91 & 0.03 & 1.45 & 0.25 & 0.77 & 0.47 \\
\hline Year; leach & 4 & 1.77 & 0.16 & 0.61 & 0.66 & 0.16 & 0.96 \\
\hline Season; year & 2 & 2.93 & 0.07 & 1.25 & 0.30 & 0.13 & 0.87 \\
\hline Year; season; leach & 4 & 1.54 & 0.21 & 0.50 & 0.74 & 0.01 & 1.00 \\
\hline Slope & 1 & 169.58 & $<0.001$ & 7.53 & 0.01 & 585.40 & $<0.001$ \\
\hline Year & 2 & 6.96 & 0.00 & 0.27 & 0.77 & 3.20 & 0.05 \\
\hline Season & 1 & 29.42 & $<0.001$ & 0.07 & 0.79 & 1.22 & 0.28 \\
\hline Year; season & 2 & 5.64 & 0.01 & 0.28 & 0.76 & 2.17 & 0.13 \\
\hline Leaching & 2 & 1.09 & 0.35 & 0.22 & 0.80 & 0.98 & 0.39 \\
\hline Year; leach & 4 & 0.23 & 0.92 & 0.11 & 0.98 & 0.70 & 0.60 \\
\hline Season; year & 2 & 0.45 & 0.64 & 0.47 & 0.63 & 1.37 & 0.27 \\
\hline Year; season; leach & 4 & 0.34 & 0.85 & 0.12 & 0.97 & 1.49 & 0.22 \\
\hline R square & & \multicolumn{2}{|c|}{0.98} & \multicolumn{2}{|c|}{0.88} & \multicolumn{2}{|c|}{0.99} \\
\hline Root mean square error & & \multicolumn{2}{|c|}{1.71} & \multicolumn{2}{|c|}{34.64} & \multicolumn{2}{|c|}{3.00} \\
\hline Mean of response & & \multicolumn{2}{|c|}{4.84} & \multicolumn{2}{|c|}{50.77} & \multicolumn{2}{|c|}{12.09} \\
\hline Variation coefficient & & \multicolumn{2}{|c|}{35.38} & \multicolumn{2}{|c|}{68.22} & \multicolumn{2}{|c|}{24.82} \\
\hline
\end{tabular}




\section{Discussion and conclusions}

Considering the whole outcome of the experimental trial, the following remarks can be outlined.

The intensive agricultural use of the soil, when exposed to frequent rotations of crops constantly irrigated with low quality water during the spring-summer months, is a matter of great concern; under these conditions, the occurrence of an unsustainable soil salinity level is quite certain, unless a sufficient amount of precipitations does not re-establish the salt equilibrium.

This scenario is clearly demonstrated by our results with reference to the salt built-up during the $S 1$ periods. A single spring-summer cropping cycle could be sufficient to bring about severe salinity conditions, particularly when: the irrigation water is characterized by high electrical conductivity (5-6 dS m $\mathrm{m}^{-1}$ ), the required $E T_{c}$ is high and the total amount of water delivered is in the range of $400-500 \mathrm{~mm}$, the average soil salinity is already high at the beginning of the cropping season.

Nevertheless, both in tomato and zucchini, unacceptable $E C_{e}$ levels were attained only at the end of cropping season. This consideration suggests to delay leaching to the following $S 2$ season, thus avoiding an extrawater application during a period of the year characterized by large evaporation requirements and huge crop water consumptions (thus greatly increasing the leaching water volumes). This strategy can be easily applied to crops that are not too sensitive to soil salinity (like tomato and zucchini). Another reason to postpone leaching, as demonstrated by our work, is related to its effectiveness: the higher the soil salinity, the higher is the amount of salts displaced from the active soil profile per unit volume of drained water. The salt already present in the soil $\left(S_{0}\right)$ and those added by irrigation $\left(S_{I N}\right)$ play an important role in improving salt removal effectiveness. A dynamic leaching strategy is thus suggested: to operate soil salt leaching not at every crop watering but only when the soil salinity is close to a dangerous level, jeopardizing crop yield.

The most effective salt reduction in the soil profile occurred during the autumn-winter period, thanks to rainfalls. When a year of very abundant precipitations occurs, soil leaching and drainage allow a significant salt discharge from the soil and the restoration of salinity conditions that are not limiting to crop productivity. This particular conditions were experimentally observed in the second and third year of the experiment; as a consequence, conditions of salt equilibrium were almost reached. However, rain is usually not sufficient to ensure soil leaching; without intentional leaching there are generally no chances to remove the accumulated salts.

The leaching treatments performed during the three-year trial had no statistically significant effect; this can be explained through two reasons: the exceptionally high rain amounts reduced the frequency of intentional leachings and the unintentional leaching carried out by precipitations almost totally offset the results of the few intentional leachings.

Avoiding leaching in the course of the spring-summer season postpones the problem of salt removal from the soil to the following autumn-winter season. In such circumstances, two different options are possible (Figure 2), depending on the crop rotation: i) if the soil, in the course of the autumn-winter period, is going through a fallow, waiting for the following spring cropping cycle, a leaching application is not particularly urgent and time is still available to rely on the expected rains; ii) otherwise, if an autumn cropping cycle is just starting (the same circumstances faced in the experiment with spinach and broccoli) it could be useful to mitigate soil salinity with leaching, in order to avoid crop failure, particularly in the first and more vulnerable stages of germination and emergence. Differently for spinach and broccoli, wheat is very tolerant to salinity and its cropping cycle can be considered the same of a fallow period.

Intentional leaching application could be preferentially performed in
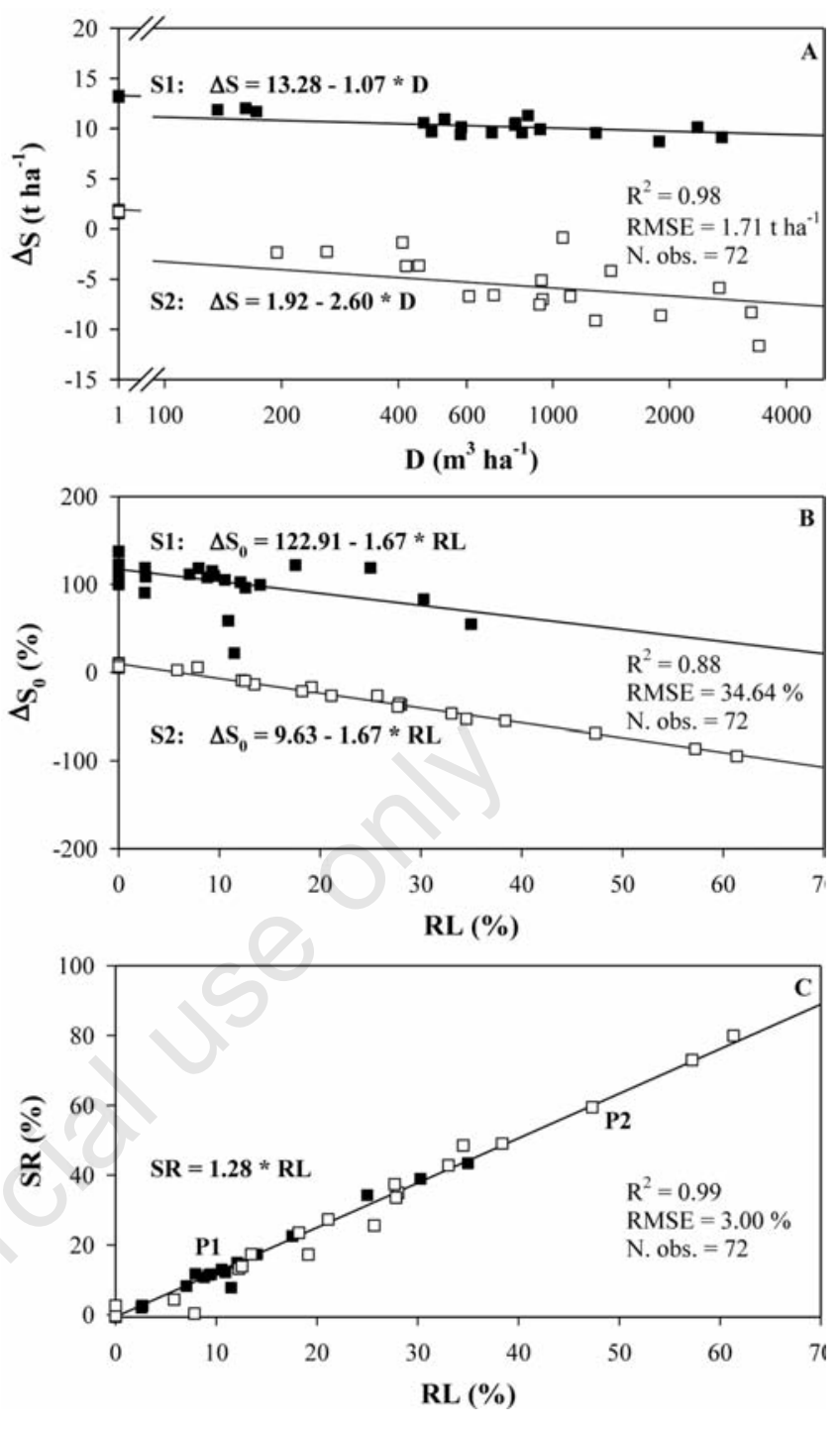

Figure 6. Set of linear regressions as a result of the ANCOVA on soil salinity balance: $\mathrm{A}$ ) variations in soil salt content $(\Delta S)$ related to the corresponding (log scale) drainage volumes (D); B) relative variations in soil salt content $\left(\Delta S_{0}\right)$ with respect to the corresponding relative leaching volumes $(L R)$; C) salinity ratios $(S R)$ as function of relative leaching volumes $(L R)$. Symbols relate to data averaged by year and leaching treatments

the course of the fallow periods: at the end of $F 1$ a sort of precautionary leaching should be carried out, just before the autumn-winter rains start falling, using fresh or brackish water (according to the available water quality); a second possible and final (or consumptive) leaching could be eventually performed at the end of $F 2$, soon after the autumnwinter rains, in case their amount was not sufficient to achieve salt removal from the soil; only water of good quality is to be employed in this latter case, because sowing or seedling transplanting are very close in time.

The simple and comprehensive leaching model (Figure 6C) is to be used to plan, do and check salt leaching from the soil. Under the experimental conditions, an annual steady-state salinity control at $E C_{e}$ around 5-6 dS m${ }^{-1}$ requires, at least, $310 \mathrm{~mm}$ of fresh drainage water; if $200 \mathrm{~mm}$ of brackish water are also available as extra-irrigation supply, the amount of fresh drainage water is reduced to approximately 170 $\mathrm{mm}$. If rains were not efficient to play this crucial role, additional leaching irrigation should be performed. 
It can be concluded that, in order to prevent soil salinity build-up to levels limiting crop productivity and maintain salt equilibrium, a recommended strategy is to supply an extra amount of fresh irrigation water before or, alternatively, after the autumn-winter rains (precautionary and consumptive leaching, respectively). The larger is the seasonal rainfall and the available brackish water, the less amount of fresh water will be needed to promote leaching. These operational criteria allow to preserve the equilibrium conditions between irrigation and drainage as well as the sustainability of irrigated agriculture.

\section{References}

Allen GR, Pereira L, Raes D, Smith M, 1998. Crop evapotranspiration. Guidelines for computing crop water requirements. Irrigation and Drainage paper n. 56. FA0 Publ., Roma, Italy.

Barnard JH, van Rensburg LD, Bennie ATP, 2010. Leaching irrigated saline sandy to sandy loam apedal soils with water of a constant salinity. Irrig Sci. 28:191-201.

Bertlan JM, 1999. Irrigation with saline water: benefits and environmental impact. Agr. Water Manage. 40:183-194.

Chen W, Hou Z, Wu L, Wei C, 2010. Evaluating salinity in soil irrigated with saline water in arid regions of northwest China. Agr. Water Manage.97:2001-2008.

Corwin DL, Rhoades DJ, Simunek J, 2007. Leaching requirement for soil salinity control: steady-state versus transient models. Agr. Water Manage.90:165-180.

Hamdy A, 1994. Saline irrigation management for a sustainable use Proc. 8th World Congr. on Water Resources. Special Session: irrigation network activities, Cairo, Egypt.

Hamdy A, 2002. Saline irrigation management for a sustainable use. In: Mediterranean crop response to water and soil salinity, ecophysiological and agronomic analysis. CHIEAM, Bari. Option Méditerranéennes B 36:185-230.

Hillel D, 2000. Salinity management for sustainable irrigation. Integrating science, environment abd economics. The World Bank, Washington, DC, USA.

Letey J, 1993. Relationship between salinity and efficient water use. Irrigation Sci. 14:75-84.

Libutti A, Florio M, Monteleone M, Disciglio G, Tarantino E, 2008. Hydro-salinity balance to monitor soil salinity at field scale due to brackish irrigation water. Option Méditerranéennes A 84:301-309.

Maas EV, Grattan SR 1999. Crop yields as affected by salinity. In: RW Skaggs and J van Schilfgaarde (eds.) Agronomy Monography No. 38. American Society of Agronomy Publ., Madison, WI, USA, pp 55-108.

Mass EV, Hoffman GJ, 1977. Crop salt tolerance-current assesment. J Irrig. Drain. E-ASCE 103:115-134.

Minhas PS, Tyagi NK, 1998. Guidelines for irrigation with saline and alkali waters. CSSRI Bulletin, Karnal, India.

Minhas PS, Sharma OP, Patil SG, 1998. Twenty-five years of research on management of salt-affected soils and use of saline water in agriculture. CSSRI, Karnal, India.

Monteleone M, Del Vecchio S, Basso G, Cucci G, De Caro A, 2003. Stima della conducibilità elettrica dell'estratto di pasta satura in base a differenti rapporti di diluizione dei campioni di terreno. pp 265-266 in Atti XXXV Convegno della Società Italiana di Agronomia "Obiettivo qualità integrale: il ruolo della ricerca agronomica", Portici (Na), Italy.

Monteleone M. Garofalo P, Tarantino E, 2004a. Caratterizzazione del clima di Foggia: analisi di un cinquantennio di rilevazioni meteorologiche, dal 1951 al 2000. Volume edito con il contributo dell'Università di Foggia e dell'Associazione "Soroptimist International", club di Foggia. ISBN 88-7427-003-8.

Monteleone M, Gatta G, Giuzio L, La Rotonda P, De Caro A, 2004b. Effect of leaching on salt accumulation in the soil under brackish water irrigation. pp 102-112 in Proc. Int. Workshop and Special Session on Management of poor quality waters for irrigation, 55th IEC Meet. Int.l Commission on Irrigation and Drainage (ICID), Moscow, Russia.

Monteleone M, 2006. Salinity management in Southern Italy irrigation areas. Ital. J. Agron. 1:129-202

Monteleone M, Florio M, de Simone G, De Caro A, 2006. Irrigation salinity scenario. A long term simulation on Mediterranean conditions. Proc. 9th Conf. European Society of Agronomy, Warszawa, Poland 11:175-176

Naresh RK, Minhas PS, Goyal AK, Chauhan CPS, Gupta RK, 1992. Production potential of cyclic irrigation and mixing of canal and saline waters - in Indian mustard - Pearl millet rotation. Arid Soil Res. Rehabil. 7:103-111.

Rhoades J. D., Manteghi N. A., Shouse P.J., Alves W.J. 1989. Soil electrical conductivity and soil salinity: New formulations and calibrations. Soil Sci. Soc.Am. J. 53:433-439.

Rhoades JD, Loveday J, 1990. Salinity in irrigated agriculture. In: A Stewart and DR Nielsen (eds.) Irrigation of Agricultural Crops. No. 30 series Agronomy. American Society of Agronomy Publ., Madison, WI, USA.

Schoups G, Hopmans JW, Young CA, Vrugt JA, Wallender WW, Tanij KK, Pandai S, 2005. sustainability of irrigated agriculture in the san Joaquin Valley, California. PNAS 102:15352-15356.

Tanji KK, 1990. Nature and extent of agricultural salinity. In: KK Tanji (ed.), Agricultural Salinity Assessment and Management. American Society of Civil Engineers Publ., New York, NY, USA, Manual and Report Engineering Practice 71:71-92.

US Salinity Laboratory Staff, 1954. Diagnosis and improvement of saline and alkali soils. USDA Agriculture Handbook No. 60. US Government Printing Office, Washington, DC, USA.

van Hoorn JW, van Alphen JG, 1994. Salinity control. In: HP Ritzema (ed.) Drainage principles and applications. Int. Inst. of Land Reclamation and Improvement (ILRI) Publ., Wageningen, The Netherlands, pp 553-600. 